\title{
Variety of Methodological Approach in Economics
}

\author{
Sheila C Dow
}

\begin{abstract}
It has been argued by some that the distinction between orthodox economics and heterodox economics does not fit the growing variety in economic theory, unified by a common methodological approach. On the other hand, it remains a central characteristic of heterodox economics that it does not share this methodological approach, but rather represents a range of alternative methodological approaches. The paper explores the evidence, and arguments, for variety in economics at different levels, and a range of issues which arise. This requires in turn a discussion of the meaning of variety in economics at the different levels of reality, methodology, method and theory. It is concluded that there is scope for more, rather than less, variety in economic methodologies, as well as within methodologies. Further, if variety is not to take the form of "anything goes", then critical discussion by economists of different approaches to economics, and of variety itself, is required.
\end{abstract}

Key words: Pluralism, methodology

JEL Classification: B41, B0, C0

* This paper has benefited from discussions following presentation of related work at Queen's University, Belfast, at the University of Ljubljana, at the 'Dissent in Science' Seminar at the LSE, at the University of Bath and the University of Liverpool, and comments from Victoria Chick, John Davis, Alexander Dow, Miguel Duran, Tatiana Kornienko and Warren Samuels. A sister paper arising from this work is Dow (2006).

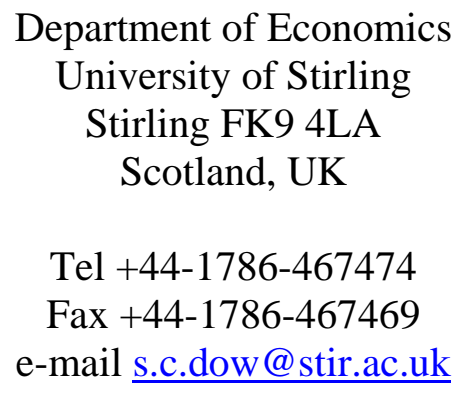

October 2006 
The discipline of economics is continually changing, requiring a re-examination of the concepts of orthodox economics and heterodox economics. The particular feature of recent change which this paper examines is the appearance of increasing variety, or plurality, in economics, in particular in economic theory, and what this implies for heterodox economics.

In this exercise, we can benefit from the unusual degree of reflection on the state of economics during the recent millennium. Weintraub’s (1999) approach to the subject explicitly drew on modern developments in historiography, which acknowledge that different histories can be written from different perspectives; no historical account can claim to be the one "true" account. The emphasis therefore was on the variety of perspectives in economics and, by implication, variety in economics itself. Indeed, such an account provides implicit support for pluralism, ie the argument for, or celebration of, variety. But if economics is pluralistic, how are we to understand it as a discipline? And does plurality spell the end of methodology on the one hand, or set out an agenda for a new methodological discourse on the other? Does plurality mean that criticism has no role ("anything goes"), or does it require a redrawing of the framework for criticism? What opportunities are offered by pluralism?

The role for plurality had already arisen in earlier exercises in looking forward to the future of economics. In 1991, the Economic Journal marked the occasion of the first issue of its second century by inviting leading economists to reflect on what the future held for the discipline. Among the prescient themes which emerged were the following, each of which was explored by several contributors:

- the opening of economics to input from, as well as input to, other disciplines, notably sociology and psychology (see also Allen, 2000); 
- increasing specialisation within economics (and thus of conferences, journals etc) leading to fragmentation of the community of economists;

- increasing cohesion around methodological and theoretical principles, with a move away from the type of divide seen in the Monetarist-Keynesian debates.

John Pencavel (1991) concluded that these seemingly opposing trends would be compatible if we think of economic ideas as being diverse and competing freely in competitive markets. He used the term "pluralistic" to describe the outcome, which he welcomed as reducing the scope for “[p]rofessional tyranny” (Pencavel, 1991, p.87), by implication an imperfection in the market for ideas. But plurality is not universally welcomed, since it raises concerns as to how the different types of theory can be put together. Blanchard and Fischer (1989, p.505), for example, had referred to it as being "logically uncomfortable".

The concept of plurality has been explored more widely in recent years, both within and beyond economics. It is conventional now to remark that we live in a pluralist society, for example. Since economics is a social science, and particularly given the greater interface with sociology, it would not be surprising to find evidence of plurality also in economics. But there has further been the development in the economic methodology literature of the argument for plurality, ie pluralism. This literature, further, has clarified the different meanings of the term, out of which we might understand the different identifications of, and attitudes towards, plurality, as well as its implications. These developments in the field of methodology are just part of the increasing specialisation within fields in economics, which itself raises issues of meaning, and thus of communication.

The purpose of this paper is to try to overcome some of the communication difficulties across specialisations (including methodology) in order to consider variety 
in economics. First we review the evidence on variety. We then probe further what is meant by plurality at different levels which need to be distinguished (reality, methodology, method, theory), and then consider the arguments for and against pluralism, starting with Caldwell's (1982) seminal contribution to the modern discourse. This discussion throws the spotlight on a range of important issues, including the relation between mathematical formalism and plurality. We also consider schools of thought as a particular form of plurality. Here it is relevant to consider the role of Kuhn's analysis in relation to plurality and pluralism. In particular, while the arguments for plurality are strong, it is argued further that unstructured pluralism or eclecticism, understood as an absence of selection criteria, or "anything goes", is antithetical to the building up of knowledge.

It is concluded that it would be helpful (for our understanding of the current state of economics with its variety of approaches to theory and evidence, for communications between different approaches, and for future developments in the discipline) for the scope for both openness and constructive critique to be more widely discussed. This would imply that more economists be aware of, and discuss more, the architecture of the discipline. Indeed, it will be argued that, while we observe variety at the level of theory and evidence, the reasons for such variety also justify variety at the level both of method and of methodology. While their characteristics may change, the concepts of orthodox economics and heterodox economics are still relevant as a way of capturing variety at the meta-methodological level. 


\section{I . EVIDENCE OF PLURALITY IN ECONOMICS}

We start by considering how far, and in what way, economics may be said to be pluralistic, drawing on the wide range of commentaries which have appeared in the recent literature. In order to consider how far modern economics is fragmented, it is useful to compare it with the recent history of economics, and indeed most of these commentaries have taken such an approach.

The conventional account (see for example Colander, 2000a, and Goodwin, 2000) characterises the 1970s-1980s as a period of fierce debate between different schools of thought, often epitomised by the Monetarist-Keynesian debates. The differences are characterised as being policy-focused and, ultimately, ideological. But contemporary accounts from that period identified a wider range of schools of thought, which were differentiated more by methodological approach than by ideology alone: mainstream economics, Post Keynesian economics, institutionalist economics, neo-Austrian economics, Marxian economics, and so on. There were differences as to how to characterise mainstream economics. Weintraub (1985) and Backhouse (1991) saw it as being unified in terms of the principles of general equilibrium theory (see also Dow, 1985). But Phelps (1990), Mair and Miller (1990) and later Snowdon, Vane and Wynarczyk (1994) could identify schools of thought within mainstream economics (such as monetarism, new classical economics, real business cycle theory and new Keynesian economics).

The most notable change identified in the literature some twenty years later has been a process of increasing fragmentation within mainstream economics, going beyond the schools of thought identified earlier. Colander (2000b) for example focused on the movement of economics in the direction of handling increasing complexity. He noted a growing divergence from formal general equilibrium models 
for policy purposes, which was inevitably a force for fragmentation, and predicted a move towards more contextual microfoundations, which would reinforce that trend. He had already announced the “death” of neoclassical economics as a useful category (Colander, 2000a). As predicted in the centennial Economic Journal issue, the growth of game theory, experimental economics, evolutionary economics, behavioural economics, complexity economics, and so on, had meant that the mainstream of economics could no longer be identified as a single theoretical system.

Davis (2006) offers an explanation for this development in terms of a cyclical process of trade in ideas, whereby variety emerges when imports exceed exports. Thus, many of these developments in mainstream economics can be seen as an adaptation designed to incorporate ideas from other approaches in economics (which had been questioning the rational economic man concept, for example) or other disciplines (such as psychology and biology). Since many of these developments have encroached on the middle ground between mainstream economics and nonmainstream schools of thought, Goodwin (2000) questions whether there is any continuing relevance in these two categories (see further Coats, 2000). The character of plurality in economics had changed.

This plurality of theories is also evident in their content, and the changing nature and scope of evidence, reflecting an increasing understanding of plurality in the subject matter. Thus, by considering the possibility of different information sets among different categories of economic actor, rational expectations theory generated multiple equilibria. This outcome jeopardised the clear implications which had earlier been drawn from the strong rational expectations hypothesis. Similarly, behavioural economics took on board different attitudes to risk in order to explain more complex behaviour in financial markets. Game theory took on the implications of interaction 
between different interest groups, and so on. This increasing focus on heterogeneous agents reflects a movement away from the idea of the representative agent in an effort to capture more effectively a complex reality (see for example Kirman, 1992). Thaler (2000) predicts a continuation of this trend. In the meantime, theory change has been prompted by new types of evidence that have been gathered on the basis of experiments (Morgan, 2005, Sugden, 2005). Further, happiness studies have gathered new survey evidence which challenges conventional utility theory (Frey and Stutzer, 2002). Survey evidence similarly has also opened up labour market analysis to concepts (such as self-worth) outside the conventional framework (Bewley, 1995).

Nevertheless some see the resulting complexity of the disciplinary landscape as being unified by the shared purpose of a general systematisation of agents' rational behaviour (however defined) under certainty and uncertainty conditions, including interactive behaviour (Giocoli, 2003). Indeed, while there is a consensus that there has been fragmentation in terms of theory and evidence, there is also a consensus in the literature that there has been a growing cohesion at the level of approach, specifically in terms of method selection. Thus Blanchard, who with Fischer had drawn attention to the plurality within macroeconomics in 1989, as we noted above, had by 1997 come to emphasise the commonality at the level of framework (Blanchard 1997, p.582). More generally, Goodwin and Colander point to the increasing requirement for theory to be expressed in terms of formal mathematics, which at the level of method reduces significantly the degree of plurality. Indeed the consensus identified by commentators (such as Morgan and Rutherford, 1998, and Blaug, 1999) has been that constructing, analysing and testing formal models is the core activity of mainstream economics. Indeed, as Becker (1976, p.5) put it: “what distinguishes 
economics as a discipline from other disciplines in the social sciences is not the subject matter but its approach”.

Thus game theory has evolved by formalising different notions of rationality (Samuelson, 2004). In behavioural economics, the notion of "rational” behaviour has been extended to incorporate what had once been dubbed "irrational”, such as timeinconsistency and self-control. But the outcome is still expressed in terms of optimising behaviour subject to constraints, such that it is amenable to formal treatment (eg Samuelson and Swinkels, 2006). The conventional mainstream notion of uncertainty (ie risk) has been refined, now incorporating experienced uncertainty, as well as decision uncertainty (eg Kahnemann and Sugden, 2005), but again still applied within a utility maximisation framework. Institutional and conventional considerations are being given more prominence in labour market analysis. For example Thomas (2005) analyses labour market behaviour focusing on the idea of the fair wage (and thus wage relativities). But the analysis still rests on a utilitymaximising framework where such considerations do not appear in the utility function. Similarly it is not clear how the evidence on happiness will be translated into theory, not least because of the subjective nature of the evidence. We seem still to be in Blanchard and Fischer’s “logically uncomfortable” territory.

Samuelson (2005) explains the challenges such developments pose for a formalist approach, exploring in detail the difficulties in combining the apparently conflicting insights from experimental economics with theory. For example, how far are surprising results from experiments still conditioned by the abstractions of the theory to which they related, and therefore do not constitute independent evidence? How should preferences be modelled when going beyond a narrow conception of selfinterest? The importance of addressing such difficulties is emphasised when he 
concludes that "at some point some connections must be made between theory and behaviour if economic theory is not to fade into either philosophy or mathematics" (Samuelson, 2005, p.100). The key question will therefore be how far the requirements of mathematical modelling are given priority in resolving the emerging incompatibilities between theory and evidence. There are after all other approaches available outside the optimising-individual framework, as in Davis (2003) on rational behaviour, and the two different treatments of the labour market in Chick (1983) and Nelson (1996). These approaches differ in giving formal models a partial role alongside other methods of analysis (or even no role). Unlike conventional theory, the model solution is not regarded as necessarily the definitive solution. One critical consequence of defining economics by a particular methodology, as in mainstream economics, is that such alternatives may not be recognised as even falling within economics. The homogeneity of methodological approach is then self-reinforcing.

Given the importance, therefore, of unity of method (alongside plurality of theory and evidence), we turn now to analyse its justification, as well as significance and implications. In particular it is important, given the diverging trends in terms of theory/evidence and method, that it be clarified what is entailed by plurality at different levels. We do this in the next section, and at the same time consider the arguments put forward for plurality, that is, for pluralism.

\section{VARIETY AT DIFFERENT LEVELS}

We have already seen evidence of a consensus that there is increasing plurality in the practice of mainstream economics and unity in terms of methodology. So we also need to consider the relations between the levels, the meaning of plurality at the level of reality, and distinguish between a plurality of methodologies, or approaches, on the 
one hand and a methodology which advocates a plurality of methods on the other (Dow, 2001).

We start with the subject matter of economics: reality, and the nature of social systems, of which the economy is a part. The nature of reality in turn determines what kinds of knowledge are possible. It is difficult definitively to separate the level of reality from the level of our knowledge about it. Nevertheless, it is possible to make statements about what we understand as the nature of reality, and about what that implies for possibilities for knowledge. The question at issue here is whether or not there is an underlying unity to social systems. If there is, then behaviour is law-like, and it is the task of economics to uncover those laws. There is little scope for diversity of opinion, or plurality in terms of knowledge, except in the transitional state during which laws are being uncovered. Put another way, closed social systems allow for the identification of laws on the basis of which predictions can be made with confidence.

On the other hand if there is diversity in nature, that is behaviour is not lawlike, then there is scope for variety of opinion (that is, plurality of knowledge), and thus a range of possible explanations for economic outcomes (Runde, 1998). This would also be the case, even if there is unity in nature, if there are difficulties in observing nature. Open systems, which allow for human agency (creativity, the nondeterministic exercise of choice etc) and the (indeterminate) evolution of the institutional structure within which individuals exercise agency, do not have the invariant kind of causal mechanisms which yield up laws, and allow instead for a plurality of explanations and modes of explanation (Davis, 2003; Chick and Dow, 2005). Many economists would agree with Popper (1982) that reality is an open system (or at least, if a closed system, that signals are too noisy to allow us to identify it). For example, such thinking lies behind Colander's (2000b) prediction that 
economics will increasingly focus on the particularity of institutional context, so that we can expect increasing variety in knowledge.

For world-truth realists, reality is the arbiter of opinion: knowledge can only be regarded as true or false by reference to reality (Mäki 1988). Positivism saw world truth realism as ensuring unity of knowledge through empirical testing (only one opinion could be correct). But it became clear that empirical testing was not definitive in settling disputes in science more generally or in economics in particular. The problems ranged from the difficulty of identifying precisely which element of a hypothesis accounted for falsifying evidence and should be abandoned (the "DuhemQuine problem”), to the inability to test all theoretical statements, to more practical issues such as data compatibility. In charting the decline of positivism in philosophy of science, Caldwell (1982, p.244) concluded that “[t]he most significant contribution of the growth-of-knowledge philosophers was the demonstration that the quest for a single, universal, prescriptive scientific methodology is quixotic”.

Different methodologies can be seen to follow from different understandings of reality. Thus, for example, market economies can be understood to be inherently stable (such that deviations from trend are understood as resulting from shocks, as in the new growth theory) or inherently unstable (as in the Keynes/Minsky theory of the business cycle). From each view of reality follows a different view of how best to build knowledge about it. A stable New Keynesian system with all variables, including shocks, identified (a closed system) lends itself to mathematical modelling which yields a precise conclusion. On the other hand, the focus of the Keynes/Minsky approach on the indeterminate nature of the timing and amplitude of the cycle, and the central role given to unquantifiable risk, explains the more partial role for formal models (without optimising behaviour) alongside other methods of analysis (see eg 
Dow, 1998; see Lucas, 1980, for a different view). From these different methodologies stem different selection and use of methods, and different theories.

We can identify four arguments for variety in methodological approach, which we will discuss in turn below. The first is to accept its existence as a feature of knowledge systems on ethical grounds, whether or not it is justified. The second is to argue that no mechanism exists for unifying knowledge about reality, so we have no choice but to accept plurality of approach. The third is to argue that plurality of approach inevitably follows from the nature of the subject matter, and the fourth is positively to advocate plurality on the grounds that variety is essential to the survival of the discipline in the face of an evolving subject matter.

The ethical argument rests on what is seen as a fundamental aspect of knowledge (Screpanti, 1997; Mäki, 1997; McCloskey, 1994). If at a basic level we can construct knowledge in different ways, for whatever reason, and there is no agreed basis for identifying one best approach to knowledge, then there can be no justification in presuming that others' approach to knowledge will be the same as our own. To recognise this requires an awareness that reality may be understood differently, terms may be used with different meanings, different criteria employed for deciding what is a good argument, and so on. The ethical argument then is to develop sufficient awareness of difference, first to recognise other approaches, and second not to reject them simply because they are different. This is not at all to rule out criticism. On the contrary, it is argued that critical analysis which is as "objective" as possible requires some mutual understanding (of methodological principles, meaning, etc).

When Morgan and Rutherford (1998, p.8) identified a change in the professional ethos of American economics away from interwar pluralism, they 
characterised it in terms of a move away from associating objectivity with evenhandedness with respect to different arguments (and different types of argument). Even-handedness requires awareness of “otherness”. Morgan and Rutherford identify modern economics with the rise of technocracy, and an association of objectivity instead with the adoption of a particular range of techniques. These techniques facilitate direct comparability of argument, but at the cost of precluding arguments which cannot be expressed in terms of these techniques. This approach is monist (ie discourages variety) with respect to methodological approach. Further the particular methodology itself is monist in content in making mathematical modelling the one general core method.

This increasing monism in terms of methodological approach has therefore allowed the emergence of a plurality of theoretical approaches, using different subsets of formal techniques. But at the same time, it has created a dualistic divide between theories which conform to these norms of development and expression and those which do not, discouraging mutual understanding and communication. There is an asymmetry in that, for mainstream economics, the formalist methodological approach defines the discipline, and thus excludes heterodox economics; for other approaches, economics is defined by subject matter, and thus includes orthodox economics. The ethical argument for pluralism suggests that even-handedness of treatment of different arguments should allow, not only for different theories within one definition of objectivity, but also for other concepts of objectivity. The partial role given to mathematical modelling (or even its absence), along with other methods of analysis, in other approaches indicates variety of methodological approach but also variety within those approaches. 
In society at large, awareness of variety of approach to knowledge (as part of a more general awareness of otherness) rose in the 1960s, encouraged by Kuhn's philosophy of science, and later in more extreme form with postmodernism. Kuhn’s (1962) paradigm framework was part of the movement away from positivism laying down the principles of best practice in science. Kuhn's history of science demonstrated that science evolves within communities with shared understandings of reality, shared views as to how to construct knowledge and shared understandings of terms. Interestingly, he suggested that the initial spur to his work came from the realisation that later astronomers claimed that Aristotle's reasoning was nonsense because they were applying their own, different, meanings to his terms; to understand Aristotle required an understanding of his different knowledge framework (Kuhn, 1990). According to Kuhn, science progresses within dominant paradigms, which are replaced with new paradigms when anomalies with respect to reality become insupportable. With the new paradigm, terms take on new meanings and criteria for good arguments change. Knowledge drawn from different paradigms is thus “incommensurate”.

Kuhn was generally disregarded by those economists who misunderstood him as a relativist, advocating “anything goes” (although the concept of paradigm shift has been widely used in accounts of economics in the twentieth century). The difficulty was that, if it is accepted that positivism does not provide a secure basis for knowledge, and there is no other incontestable candidate for the best approach, then it did indeed seem that “anything goes”.

But there has recently been a revision to the view that Kuhn therefore had very limited impact on economics. Fuller (2000, 2003) argues that this extreme relativist (mis)understanding of Kuhn encouraged a withdrawal from methodological 
discussion altogether. Such a move was advocated most publicly by Friedman (1953), who argued that theories should be judged only by their predictive power. Making the case for an end to prescriptive methodology, McCloskey (1983) argued that economists persuade by means of rhetoric rather than methodological principle. The implication was that economists did not need to reflect on methodology, nor to justify their theories with reference to any methodological principles. This may have proved to be telling for the subsequent fragmentation of mainstream economics, as well as the relative lack of discussion about it, but does not explain the increasing homogeneity at the level of general method.

In the meantime, postmodernism also influenced to some extent the content of economic theory. For those who understand knowledge of reality as being sociallyconstructed, there is no independent account of reality which would allow a return to an empirical criterion, reinforcing the view that pluralism of approach is the only option (Samuels, 1998). Thus Phelps (1990) for example identified the rational expectations approach with postmodernism, because of the subjective nature of expectations, something explored more thoroughly with respect to Sargent's thought by Sent (1998). Along with the view that there was no one incontestable understanding of the economy by economists, the practice developed of understanding the expectations of economic agents as also being subjective and thus open to variety, or plurality.

But there was also an argument for a more limited form of plurality of approach which did not adopt the methodological agnostic view (inappropriately) associated with Kuhn (Dow, 2004b). The emphasis here was on the limitations on variety imposed by the social nature of science, ie focusing on Kuhn's emphasis (following Popper) on scientific communities. There is a limit to how far there can be 
plurality of understandings of the nature of reality, approaches to knowledge, and meaning, when knowledge needs to be developed within groups of researchers and communicated to others. Plurality in practice cannot be infinite.

Further, the emphasis on the social nature of scientific activity has encouraged attention on the sociology of the discipline, so that much of the activity within economic methodology now is some form of science study, concerned with understanding the choices made by economists in developing theory and the means by which they persuade others to accept their theories. This work draws on a rich seam in what is generally classified as the Sociology of Scientific Knowledge (SSK; see Hands, 2001, chapter 5, for a survey). A key concept in this literature, which has caused considerable problems for its application, is reflexivity. In particular, no commentary on an approach to economics can be objective in the sense of not itself employing an approach. The notion of a market for economic ideas, for example, is not objective, given the range of understandings of markets in the literature (see for example Vickers, 1995; Mäki, 1999; Milberg, 2001). Thus it is highly problematic to contemplate a market for ideas as a satisfactory arbiter of ideas about markets. Nevertheless the SSK approach provides a vehicle for analysing the community of economists as a society, including the way in which methodological norms are adopted and propagated.

The third argument for a plurality of approaches rests on a specific argument about the nature of the subject matter as an open system (King, 2002; Chick and Dow, 2005). The argument then is not just that there are limitations to the human capacity for knowledge which prevent us from identifying a single best approach to knowledge which would satisfactorily explain law-like behaviour. The argument is further that the nature of individual behaviour (with its social and creative aspects) is too complex 
to be predictable (even stochastically). Formal specification of the conventions and institutions which condition their behaviour to evolve in indeterminist ways, and of creativity which by definition cannot be known beforehand, cannot alone be expected to be adequate to the task. Further, while it is argued that it is part of the human condition not to have certain knowledge (or certainty equivalence), this in turn influences behaviour and the evolution of institutions. Policy-makers are then better equipped to understand that behaviour, and its consequences, if knowledge is built up from a variety of approaches, and indeed a variety of questions asked.

The fourth and perhaps strongest argument for variety of approach to economic knowledge comes from application of the biological metaphor. The argument refers to the subject matter only in the sense that theory has to adapt to new developments. In nature, diversity of species provides protection against unforeseen threats, such that if one strain succumbs to a threat, others are available to take its place. In other words, without diversity, the one dominant strain of ideas is highly vulnerable to unanticipated developments for which it cannot generate an explanation.

Within that diversity of approach, one possibility is a pluralist methodology, that is, reliance on a range of different methods, on the grounds that no one method is sufficient. These methods must be incommensurate, otherwise they would collapse into one method. Explicit adoption of this type of methodology typifies economics outside the mainstream, although there are differences with respect to the range and focus of methods employed. But McCloskey (1983) has demonstrated that, while the "official discourse" of mainstream economics conforms to formalism in terms of a particular range of mathematical techniques for formulating theory and assessing evidence, the "unofficial discourse" relies on a much wider range of methods of argument. And indeed variety of methods is implied by Collander's (2000b) 
prediction of greater context-specificity of economics, and greater focus on institutional variety. Nevertheless the SSK approach emphasises the important sociological role played by official discourse.

The benefits of plurality of method have been promoted in the monetary policy arena by the Bank of England (1999) and the European Central Bank (2000), following the conclusion that single large formal macro models had proved to be an unsatisfactory basis for decision-making in the face of the complexity (or openness) of economic reality. This conclusion finds support and elaboration, not only in looking forward to future developments in economics (as in Collander, 2000b), but also looking back to Keynes’s economic methodology. This was based on his study of probability in the sense of uncertain knowledge (Keynes 1921) (see Dow 2004a). Keynes argued that in general the confidence we have in particular conclusions increases, the more different types of argument, and sources of evidence, support it.

The relative benefits of a pluralist methodology can be understood in terms of a metaphor used by the pragmatist Peirce (Wimsatt, 1981). A pluralist methodology is represented by a rope, which is stronger than each individual strand; it is overdetermined in that any one strand breaking will not bring down the edifice of a pluralist argument. A monist methodology (that is, reliance on one broad method which is necessary and sufficient for good argument, and which involves a shared set of terms and shared meanings) is another possibility within the range offered by variety of approach. The increasing reliance on mathematical formalism in economics in the mainstream can be classified as a monist methodology, and can be compared to a pluralist methodology in terms of relative costs and benefits. In Peirce’s symbolism, a monist methodology is represented by a single chain, which is only as strong as its weakest link. 
The mathematical formalist methodology clearly has strong attractions for many economists. One of the main advantages of a monist methodology is that all arguments are commensurate. The appeal of mathematical formalism is that it puts all arguments on an equal footing, allowing direct comparison, and a straightforward check on consistency (Allen, 2000). However in an applied discipline (and even within pure mathematics) mathematical systems cannot be closed, so that internal mathematical consistency is insufficient; there inevitably remains scope for variety of opinion (Weintraub 1998, 2002). And indeed charges of logical inconsistency (as in the Cambridge controversies of the 1960s, see Harcourt, 1972, or with respect to the no-trade theorem, see Sent, forthcoming) in practice have not proved decisive. This suggests an increasing need for a different justification for arguments to be expressed exclusively in terms of mathematical modelling, if this approach is to be sustained.

The issue of justifying choice of methodology is just one of the issues which are associated with variety in economics. In the next section we consider these issues, starting with mathematical formalism.

\section{SOME ISSUES}

\section{Mathematical formalism}

A discussion of mathematical formalism, in pure theory or as the basis for empirical work, can benefit from considering plurality at different levels, as above. At the level of choice of methodology, the preference for mathematical formalism which came to dominate economics from the 1950s is generally tacit among practising economists. Indeed where it is still discussed, as in Allen (2000), it is generally in terms of the matter being settled. Yet the attitude to mathematical formalism could prove decisive 
for how the theoretical difficulties are resolved that we noted above as arising from experimental and survey evidence.

At the level of choice of specific method (within a monist, formalist, methodology), there is a range of techniques which could be employed. The reason for any particular choice of technique is also generally left tacit; this is particularly so at the general level of choosing, say, differential calculus rather than set theory. But inevitably such choice requires argument which is in some sense outside of mathematics. The choice requires reference to the nature of the subject matter and a weighing of the costs and benefits of possible methods of analysis in relation to that subject matter. The methodology then cannot itself be fully defined by mathematical formalism.

Similarly, we have drawn attention to something else which lies outside mathematics itself: the issue of meaning. The scope for different meanings itself is a source of variety, but one which is concealed if meaning is presumed to be held in common. Mathematical expression is often treated in terms of translation from verbal language to mathematical language, which is internally precise. Mathematical argument has the advantage that it can achieve more complex operations than verbal argument, retaining precision throughout. But while mathematical argument is internally precise, giving meaning to mathematics is not (Coddington, 1975). The vagueness of verbal language allows it to encompass shades of meaning, to evolve in meaning, and to combine a plurality of types of argument. But if there is variety in meaning of verbal terms, and variety in methods of argument, both are lost in an effort of translation into mathematics. Mathematical expression is therefore not neutral, but rather puts particular limits on the scope of subject matter and of argument (Chick and Dow, 2001). Most importantly, meaning in application of theory 
further remains imprecise and open to variety of opinion. The rigour required for application is different from the rigour of mathematical argument, but no less important.

But, while inspection of the leading journals supports the view that mathematical expression is indeed a common feature of mainstream economics (Backhouse, 1998), this is embedded to a greater or lesser extent within verbal argument, as McCloskey (1983) has pointed out. Indeed, the verbal content generally contains a range of types of argument. Nevertheless, since the requirement for mathematical expression is non-neutral as far as the content of argument is concerned, the verbal argument too is constrained.

But if mathematical argument needs to be supplemented by other types of argument, non-mathematical argument is required to explain why one methodological approach has nevertheless become the common source of homogeneity in mainstream economics. The explanation may be that the growing heterogeneity at the theoretical level can be counteracted by a common mode of expression, with sufficient commonality of meaning (of concepts like "rationality") to allow understanding across subfields. This would be a particular form of the more general sociological explanation that scientific communities adopt a methodology which becomes an identifying feature (and we have seen that it is conventional now to say that mainstream economics is defined by its method). The community is perpetuated by means of education through textbook exemplars, by peer review, by hiring decisions and so on. While there is a deep background to knowledge which evades articulation (Searle, 1995), a community can serve to create and perpetuate a common background among its members and recruits to support a continuation of the methodological approach. All of this is the meat of Kuhn's analysis of paradigms. 


\section{“Anything goes”}

The background to this growing homogeneity of method was the collapse of positivism, and thus of the possibility of setting up methodological principles for all of economics. The troubling implication was that the only alternative was that “anything goes” (Salanti, 1997). It is natural for economists to seek firm foundations, and to be concerned at the sense that the discipline is developing in an ad hoc manner (Blanchard and Fischer, 1989; Colander, 2000a). In particular there is a concern to be able to settle on criteria by which to gauge progress (Backhouse 2000).

But one implication of pluralism is that it is not reasonable to expect to establish common criteria for progress. What is an acceptable explanation to one may not be acceptable to others, not just because there may be different preferred methods, but also because the nature of the subject matter is understood differently, and terms are being used in different ways. A "pure” pluralist response would indeed be "anything goes", but then it is not clear that we would be left with anything which could be called knowledge.

But in practice, since most economists tend to operate mostly in one of a limited range of (shifting, open) networks with shared underpinnings, the scope for plurality is limited. There is therefore a discrete number of approaches in economics. It is therefore feasible for any economist to learn enough about alternative approaches to engage in some communication, and indeed criticism, to good effect. Indeed it could be argued that most great developments in economics occur as a result of crossfertilisation across school-of-thought boundaries (as in rational expectations theory growing out of an encounter with behavioural economics, Kantor, 1979). 
Communication is not perfect, as across language barriers, but can nevertheless achieve some mutual understanding (Rorty, 1979). There is some common basis to all of economics (as in the structure of language, to continue the metaphor) which provides the basis for communication. This hermeneutical argument supports the ethical argument for recognising plurality, and not rejecting simply on the basis of difference. But successful communication requires understanding not only of others' approaches to economics, but also of one’s own approach.

If there is a limit to the scope for substantive over-arching principles which apply to all of economics, then each approach to economics is incommensurate in the sense of not being directly comparable. But this should not be confused with internal inconsistency. As Hodgson (1997: 148-9) put it: "The role of diversity is not to sanctify or foster contradiction. Tolerance of the right of the scientist to practise, even when we may disagree with his or her views, does not imply tolerance of any method and proposition. ... Pluralism does not mean that 'anything goes'. . . . We have to recognise the immense and enduring value of pluralism within the discipline without abandoning precision and rigour in our own work.”

Surely most economists would agree with the necessity for precision and rigour. But the significance of methodological pluralism is that the meaning and application of precision and rigour may differ from one approach to another (just as Weintraub, 2002, has shown that they have changed within mathematics itself). In particular there is a trade-off between different notions of precision and rigour in application. Consider a precise projection arising from a formal model with precise assumptions, within which classical logic has been rigorously applied. Precision and rigour in this sense need to be weighed against precision and rigour as they are understood in the exercise of judgement, for example in relaxing assumptions which 
are unsustainable in practical policy application, such as ceteris paribus. Such matters are critical for example in making monetary-policy decisions (see for example Bank of England, 1999).

\section{Schools of Thought}

If economics is to operate as a collection of loose communities, rather than an inchoate plurality, then it would seem that we would be returning to the configurations of the 1970s and 1980s. That period has been identified with ideological difference, distinguished from what is seen as the more open plurality which prevails now (Goodwin, 2000; Colander, 2000a).

Goodwin (2000) identifies the declining significance of ideology in economics with a growing disengagement from the policy process, which he regrets. But this does not address the role of values more generally. Values are an inherent part of Searle’s (1995) deep background, which influences the way in which we understand the nature of reality, and build knowledge about it, and is thus endemic to our economic theorising. It is therefore inconceivable that differences in schools of thought would not have some value component. But there are different kinds of values, and it is arguably methodological values which are of greatest importance if we understand schools of thought in terms of methodological approach. As Backhouse (2005) argues, ideology may be understood quite differently in terms of the set of values which determine choice of methodology (in addition to ideology understood in terms of political preference). Mathematical formalism was seen by many as a mechanism for promoting pluralism while getting away from ideological debate. Yet mathematical formalism itself reflects what might be called an ideological choice. 
Within this general methodology, it is possible to identify groupings, around endogenous growth theory, experimental economics, behavioural economics, complexity theory and so on. Each is developing a different set of mathematical tools which effectively separates the discourse into schools of thought. The dividing lines are not strictly drawn, not least because of the agreed adherence to mathematical formalism. Implicit here also is a shared view of human nature. While the old ideas of fully-informed, rational, atomistic agents is increasingly being replaced by the idea of complex (learning, emotional etc) heterogeneous agents (Thaler, 2000), the requirement to model behaviour mathematically is an effective constraint on what can be addressed. There are other methodological approaches in economics which can also be regarded as schools of thought, for example the older forms of behavioural economics and institutionalism which quite explicitly chose an alternative to mathematical formalism in order to get round these constraints. These approaches too of course suffer from (different) constraints, yet they add to the plurality of methodology, of theory and method in economics.

The divisions between schools of thought are not rigid or impermeable, and indeed individual economists may be seen to work across such divides. But clarification of broad-brush differences in approach is a prerequisite for addressing difference (in meaning, etc) in a constructive manner. It is also useful to use the basic classification of orthodoxy/heterodoxy to capture the distinction between economics being defined by mathematical formalism, and adoption of different methodological approaches, respectively (see Dow forthcoming).

What is being portrayed here is what could be termed "structured pluralism" (Dow, 2004b). McCloskey (1994) has been concerned that we get away from structuring the discipline around schools of thought on the grounds that they inhibit 
discourse. But on the contrary it can be argued that it aids discourse if there is some basis, first for identifying, and second for understanding, the principles and perceptions underpinning others' thought, something which is impossible with an unlimited range of methodologies. It also provides the basis for effective criticism. Awareness of methodological difference is a precondition for engagement with ideas. Criticism inevitably comes from some perspective or other, without recourse to absolute principles. But, as Popper (1963) argued, it is through criticism that knowledge progresses.

\section{CONCLUSION}

We have seen evidence that there are forces for heterogeneity in mainstream economics (at the level of theory and evidence) but much less at the level of methodology. Whether or not there is agreement as to the precise account of change within the discipline, it cannot be denied that there has been change. Yet this has attracted remarkably little critical scrutiny within the mainstream of economic discourse, as if whatever change occurs must be socially optimal.

One possible explanation which can be imputed from such methodological statements as have emerged (such as Pencavel, 1991) is that there is the presumption of some sort of invisible hand at work in a market for ideas. This is a powerful metaphor to use in economics, but one which itself requires further examination, not least because ideas are not traded; there is no price mechanism through which markets might adjust. Indeed this metaphor illustrates well its own limitations. Because, given the plurality in economics, there are different understandings of market processes within different schools of thought, each would understand the operation of a market for ideas differently. In particular, those who identify limitations to the social benefits 
of free markets, and thus intervention (including intervention to promote increased competition) would be inclined to question whether the unfettered production of ideas in economics did indeed produce the optimal outcome. While this argument is ultimately circular (depending on the perspective of market adopted), so is the argument that rests on the invisible hand. Indeed the scope for different understandings of key terms is central to the nature of plurality in economics.

It has been argued here that the growing plurality in mainstream theory and evidence, prompted by the desire to capture more of the complexity of the economy, raises questions about the sufficiency of mathematical formalism as a methodological approach. In other words, there is room also for non-formalist argument, with the mainstream methodological approach only one of a range of possible approaches. In particular, the issues posed for formal modelling by plurality in mainstream theory and evidence suggest that there is scope for more plurality at the methodological level. Economic theory is facing exciting new challenges which are open to a range of methodological treatments. The scope to take up these challenges would be severely limited if there were an overriding requirement to express all theory in terms of the kind of individual behaviour which can be captured in formal mathematics (ie in deterministic form).

In practice any discipline can only function with a limited range of approaches (within which there are understandings of the economic process, shared meanings, shared views as to what constitutes good theory, etc). An absence of universal methodological principles therefore does not mean that "anything goes”, but rather a limited range of sets of such principles. This implies that there is a continuing role for schools of thought as a way of categorising these difference approaches, aiding mutual understanding, and providing the variety on which economics can build. 
But the main purpose has been to draw attention to the issues posed by current trends in economics and to encourage wider attention to them. To leave such issues unexamined is arguably to opt for "anything goes”.

\section{REFERENCES}

ALLEN, B. 2000. The Future of Microeconomic Theory. Journal of Economic Perspectives,14, 143-50.

BACKHOUSE, R. E. 1991. The Neo-Walrasian Research Programme in Macroeconomics. In N. de Marchi and M. Blaug (eds), Appraising Economic Theories. Cheltenham: Edward Elgar.

BACKHOUSE, R. E. 1998. The Transformation of U.S. Economics, 1920-1960. In M. S. Morgan and M. Rutherford (eds), From Interwar Pluralism to Postwar Neoclassicism. History of Political Economy. 30: Annual Supplement, pp. 85-108.

BACKHOUSE, R. E. 2000. Progress in Heterodox Economics. Journal of the History of Economic Thought, 22,149-56.

BACKHOUSE, R. E. 2005. Economists, Values and Ideology: A Neglected Agenda. Revue de Philosophie Economique, 11, 49-73.

BANK OF ENGLAND. 1999. Economic Models at the Bank of England. London: Bank of England. 
BEWLEY, T. F. 1995. A Depressed Labor Market as Explained by Participants. American Economic Review, Papers and Proceedings, 85, 250-54.

BLANCHARD, O. 1997. Macroeconomics, $3^{\text {rd }}$ edition. NSR NJ: Prentice-Hall.

BLANCHARD, O. and FISCHER, I. 1989. Lectures in Macroeconomics. Cambridge, MA: MIT Press.

BLAUG, M. 1999. The Formalist Revolution or What Has Happened to Orthodox Economics after World War II. In R. E. Backhouse and J. Creedy (eds), From Classical Economics to the Theory of the Firm. Cheltenham: Edward Elgar.

CALDWELL, B. J. 1982. Beyond Positivism. London: Allen \& Unwin.

CHICK, V. 1983. Macroeconomics After Keynes: A Reconsideration of the General Theory. Oxford: Philip Allen.

CHICK, V. and DOW, S. C. 2001. Formalism, Logic and Reality: Keynesian Analysis. Cambridge Journal of Economics, 25, 705-22.

CHICK, V. and DOW, S. C. 2005. The Meaning of Open Systems. Journal of Economic Methodology, 12, 363-81.

COATS, A. W. 2000. Opening Remarks for Roundtable on the Progress of Heterodox Economics. Journal of the History of Economic Thought, 22, 145-8. 
CODDINGTON, A, 1975. The Rationale of General Equilibirum Theory. Economic Inquiry, 13, 539-58.

COLANDER, D. 2000a. The Death of Neoclassical Economics. Journal of the History of Economic Thought, 22, 127-43.

COLANDER, D. 2000b. New Millennium Economics: How Did It Get This Way, and What Way Is It? Journal of Economic Perspectives, 14, 121-32

DAVIS, J. B. 2003. The Theory of the Individual in Economics. London: Routledge.

DAVIS, J. B. 2006. The Turn in Economics: Neoclassical Dominance to Mainstream Pluralism? Journal of Institutional Economics, 2, 1-20.

DOW, S. C. 1985. Macroeconomic Thought: A Methodological Approach. Oxford: Blackwell.

DOW, S. C. 1998. Knowledge, Information and Credit Creation. In R. J. Rotheim (ed.), New Keynesian Economics/Post Keynesian Alternatives. London: Routledge.

DOW, S. C. 2001. Modernism and Postmodernism: A Dialectical Analysis. In S. Cullenberg, J. Amariglio and D. F. Ruccio (eds), Postmodernism, Economics and Knowledge. London: Routledge. 
DOW, S. C. 2004a. Uncertainty and Monetary Policy. Oxford Economic Papers, 56, 539-61.

DOW, S. C. 2004b. Structured Pluralism. Journal of Economic Methodology, 11, 27590.

DOW, S. C. 2006. Plurality in Orthodox and Heterodox Economics. Presented to the Annual Conference of the Association for Heterodox Economics, London.

DOW, S. C. forthcoming. Heterodox Economics: A Common Challenge to Mainstream Economics? In E. Hein and A. Truger (eds), Money, Distribution and Economic Policy - Alternatives to Orthodox Macroeconomics. Cheltenham: Elgar.

EUROPEAN CENTRAL BANK. 2000. The Two Pillars of the ECB's Monetary Policy Strategy. ECB Monthly Bulletin, November, 37-48.

FREY, B. S. and STUTZER, A. 2002. What Can Economists Learn from Happiness Research? Journal of Economic Literature, 60, 402-35.

FRIEDMAN, M. 1953. The Methodology of Positive Economics. In Essays in Positive Economics. Chicago: Chicago University Press.

FULLER, S. 2000. Thomas Kuhn: A Philosophical History of Our Times. Chicago: University of Chicago Press. 
FULLER, S. 2003. Kuhn vs Popper. Cambridge: Icon Books.

GIOCOLI, N. 2003. Modelling Rational Agents: From Interwar Economics to Early Modern Game Theory. Cheltenham: Edward Elgar.

GOODWIN, C. 2000. Comment: It's the Homogeneity, Stupid! Journal of the History of Economic Thought, 22, 179-84.

HANDS, D. W. 2001. Reflection without Rules: Economic Methodology and Contemporary Science Theory. Cambridge: Cambridge University Press.

HARCOURT, G. C. 1972. Some Cambridge Controversies in the Theory of Capital. Cambridge: Cambridge University Press.

HODGSON, G. M. 1997. Metaphor and Pluralism in Economics: Mechanics and Biology. In Salanti and Screpanti (eds).

KAHNEMANN, D. and SUGDEN, R. 2005. Experienced Utility as a Standard of Policy Evaluation. Experimental and Resource Economics, 32, 161-81.

KANTOR, B. 1979. Rational Expectations and Economic Thought. Journal of Economic Literature, 17, 1422-41.

KEYNES, J. M. [1921]1973. A Treatise on Probability. Collected Writings volume VIII. London: Macmillan for the Royal Economic Society. 
KING, J. E. 2002. Three Arguments for Pluralism. Journal of Australian Political Economy, 50, 1-7. Reprinted in Post-autistic Economics Review, 23:5, 2004.

KIRMAN, A. P. 1992. Whom or What does the Representative Individual Represent? Journal of Economic Perspectives, 6, 117-36.

KUHN T. S. 1962. The Structure of Scientific Revolutions. Chicago: University of Chicago Press.

KUHN T. S. 1990. Remarks on Incommensurability and Translation. In R. Favretti, G. Sandri and R. Scazzieri (eds), Incommensurability and Translation. Cheltenham: Edward Elgar.

LUCAS, R. E. Jr. 1980. Methods and Problems in Business Cycle Theory. Journal of Money, Credit and Banking, 12, 696-715.

MCCLOSKEY, D. N. 1983. The Rhetoric of Economics. Journal of Economic Literature, 31, 434-61.

MCCLOSKEY, D. N. 1994. Knowledge and Persuasion in Economics. Cambridge: Cambridge University Press.

MAIR, D. and MILLER, A. G. (eds). 1991. A Modern Guide to Economic Thought. Cheltenham: Edward Elgar. 
MÄKI, U. 1997. The One World and the Many Theories. In Salanti and Screpanti (eds).

MÄKI, U. 1988. How to Combine Rhetoric and Realism in the Methodology of Economics. Economics and Philosophy, 4, 89-109.

MÄKI, U. 1999. Science as a Free Market: A Reflexivity Test in an Economics of Economics. Perspectives on Science, 7, 486-509.

MILBERG, W. 2001. Decentering the Market Metaphor in International Economics. In S. Cullenberg, J. Amariglio and D. F. Ruccio (eds), Postmodernism, Economics and Knowledge. London: Routledge.

MORGAN, M. S. 2005. Experiments versus Models: New Phenomena, Inference and Surprise. Journal of Economic Methodology, 12, 317-29.

MORGAN, M. S. and RUTHERFORD, M. 1998. American Economics: The Character of the Transformation. In M. S. Morgan and M. Rutherford (eds), From Interwar Pluralism to Postwar Neoclassicism. History of Political Economy, 30: Annual Supplement, 1-26.

NELSON, J. 1996. Feminism, Objectivity and Economics. London: Routledge.

PENCAVEL, J. 1991. Prospects for Economics. Economic Journal, 101, 81-7. 
PHELPS, E. S. 1990. Seven Schools of Thought in Macroeconomic Thought. Oxford: Oxford University Press.

POPPER, K. 1963. Conjectures and Refutations. London: Routledge.

POPPER, K. 1982. The Open Universe: An Argument for Indeterminism. London: Routledge.

RORTY, R. 1979. Philosophy and the Mirror of Nature. Oxford: Basil Blackwell.

RUNDE, J. 1998. Assessing Causal Economic Explanations. Oxford Economic Papers, 50, 151-72.

SALANTI, A. 1997. Introduction. In Salanti and Screpanti (eds).

SALANTI, A. and SCREPANTI, E. (eds). 1997. Pluralism in Economics. Cheltenham: Edward Elgar.

SAMUELS, W. J. 1998. Methodological Pluralism. In J. B. Davis, W. Hands and U. Mäki (eds), The Handbook of Economic Methodology. Cheltenham: Edward Elgar.

SAMUELSON, L. 2004. Modelling Knowledge in Economic Analysis. Journal of Economic Literature, 62, 367-403. 
SAMUELSON, L. 2005. Economic Theory and Experimental Economics. Journal of Economic Literature, 43, 65-107.

SAMUELSON, L. and SWINKELS, J. 2006. Information, Evolution and Utility. Theoretical Economics, 1, 119-42.

SCREPANTI, E. 1997. Afterword. In Salanti and Screpanti (eds).

Searle, J. R. 1995. The Construction of Social Reality. London: Free Press.

SENT, E.-M. 1998. The Evolving Rationality of Rational Expectations. Cambridge: Cambridge University Press.

SENT, E.-M. Forthcoming. Pluralisms in Economics. In S. Kellert, H. Longino and K. Waters (eds), Scientific Pluralism. Minneapolis: Minnesota Studies in Philosophy of Science.

SNOWDON, B., VANE, H. and WYNARCZYK, P. 1994. A Modern Guide to Macroeconomics: An Introduction to Competing Schools of Thought. Cheltenham: Edward Elgar.

SUGDEN, R. 2005. Introduction to the Symposium on the Role of Experiments in Economics. Journal of Economic Methodology, 12, 177-84. 
THALER, R. H. 2000. From Homo Economicus To Homo Sapiens. Journal of Economic Perspectives, 14, 133-42.

THOMAS, J. 2005. Fair Pay and a Wage-bill Argument for Low Real Wage Cyclicality and Excessive Employment Variability. Economic Journal, 115, 833-59.

VICKERS, D. 1995. The Tyranny of the Market. Ann Arbor: University of Michigan Press.

WEINTRAUB, E. R. 1985. General Equilibrium Analysis. Cambridge: Cambridge University Press.

WEINTRAUB, E. R. 1998. Axiomatisches Missverständnis. Economic Journal. 108, 1837-47.

WEINTRAUB, E. R. 1999. How Should We Write the History of Twentieth-century Economics? Oxford Review of Economic Policy, 15, 139-52.

WEINTRAUB, E. R. 2002. How Economics Became a Mathematical Science. Durham, NC: Duke University Press.

WIMSATT, W. C. 1981. Robustness, Reliability and Overdetermination. In M. B. Brewer and B. E. Collins (eds), Scientific Inquiry and the Social Sciences. San Francisco: Jossey Bass. 